\title{
Implementasi Prinsip Educational Role Di Perpustakaan Fakultas Kedokteran Universitas Gadjah Mada Berdasarkan Standar Association Of College And Research Libraries
}

\section{Rom Ubaidillah Muhammad, Sukirno}

Universitas Gadjah Mada

kirno@ugm.ac.id

\begin{abstract}
Abstrak
Penelitian kualitatif ini bertujuan untuk mengetahui bagaimana implementasi prinsip educational role/prinsip peran pendidikan yang di terapkan oleh Perpustakaan Fakultas Kedokteran Universitas Gadjah Mada berdasarkan Standar Association Of College And Research Libraries. Teknik pengumpulan data menggunakan; wawancara, dokumentasi, observasi. Teknik pengambilan informan menggunakan purposive sampling. Metode Analisis data menggunakan teori Miles dan Huberman dengan tiga langkah yaitu; reduksi data, penyajian data, serta penarikan kesimpulan dan verifikasi. Deskripsi hasil penelitian menggunakan teori tahapan implementasi dari Erwan Agus Purwanto dan Dyah Ratih Sulistyastuti dalam buku implementasi kebijakan publik. Tahapan tersebut yaitu: kebijakan: tujuan dan sasaran, keluaran dan kebijakan, implementor, kelompok sasaran, dampak jangka pendek, menengah dan jangka panjang, dan kinerja implementasi. Hasil penelitian menunjukan bahwa implementasi peran pendidikan di Perpustakaan FK UGM di implementasikan dengan program kerja pelatihan literatur searching, update modul literatur searching, bedah buku karya dosen FK, dan penyediaan fasilitas teknologi informasi untuk pembelajaran berupa fasilitas wifi, koleksi referensi online dan teknologi RFID Circulation Assistant.
\end{abstract}

\author{
Kata Kunci: \\ Implementation \\ Principle of Educational Role \\ Standards Association of College \\ Research Libraries
}

\section{Latar Belakang}

Fakultas Kedokteran UGM melakukan inovasi pendidikan dengan menerapkan pembelajaran berdasarkan masalah atau (problem based learning) secara penuh bagi mahasiswa reguler dan program internasional. Pelaksanaan (problem based learning) menekankan pada pemberian sarana-prasarana belajar peserta didik aktif mandiri, bebas dalam menggali dan membentuk kompetensi ilmu, keterampilan, sikap prilaku, kepribadian profesi kognitif, psikomotorik, afektif). Guna mendukung inovasi tersebut Perpustakaan Fakultas Kedokteran Universitas Gadjah Mada senantiasa melakukan pengembangan. Pengembangan tersebut dilakukan dengan mengacu pada standar Association Of College And Research Libraries for Higher school (ACRL) yang diterbitkan oleh
American Library Association (ALA).

Kelebihan standar ACRL dengan standarstandar perpustakaan yang lainnya adalah dalam standar ini lebih menekankan ekpekstasi dan peran inti serta kontribusi dari perpustakaan terhadap lembaga induknya. Pernyataan tersebut berdasarkan penjelasan yang dikutip dalam standar (ACRL, 2011:1) yaitu, standar ACRL ini dirancang untuk memandu perpustakaan perguruan tinggi dalam meningkatkan dan mempertahankan perannya sebagai mitra dalam pendidikan mahasiswa, mencapai misi institusi induknya, dan memposisikan perpustakaan sebagai pemimpin dalam asesman dan perbaikan berkelanjutan dikampus.

Mengacu hal tersebut diatas, maka penelitian ini dilakukan guna mengetahui bagaimana bentuk 
pengimplementasian prinsip peran pendidikan pada standar ACRL.

\subsection{Rumusan Masalah}

Berdasarkan penjelasan latar belakang diatas yang menjadi rumusan masalah dalam penelitian ini adalah bagaimana implementasi prinsip peran pendidikan di Perpustakaan FK UGM berdasakan standar ACRL.

\subsection{Tujuan Penelitian}

Tujuan dalam penelitian ini adalah untuk mengetahui implementasi dari prinsip peran pendidikan di Perpustakaan FK UGM berdasarkan standar ACRL.

\section{Landasan Teori}

\subsection{Pengertian Implementasi}

Kamus Besar Bahasa Indonesia online http:// kbbi.web.id/implementasi mengartikan arti kata implementasi adalah pelaksanaan; penerapan. Buku implementasi kebijakan publik yang ditulis oleh Purwanto dan Dyah Ratih Sulistyastuti (2012:21) mengartikan implementasi sebagai kegiatan untuk mendistribusikan keluaran kebijakan (todeliver policy output) yang dilakukan oleh para implementer kepada kelompok sasaran (target group) sebagai upaya untuk mewujudkan tujuan kebijakan.

Kegiatan implementasi kebijakan adalah cara agar sebuah kebijakan dapat mencapai tujuannya. Tujuan kebijakan diharapkan akan muncul manakala hasil kebijakan (policy output) dapat diterima dan dimanfaatkan dengan baik oleh kelompok sasaran sehingga dalam jangka panjang hasil kebijakan akan mampu diwujudkan.

\subsection{Proses Implementasi Kebijakan}

Proses kebijakan publik tidak akan bisa terealisasikan dilapangan tanpa ada kegiatan implementasi kebijakan, implementasi kebijakan ini menjadi penting karena tahapan ini merupakan jembatan antara dunia konsep dengan dunia realita. Menurut Grindel (1980) yang dikutip dalam Purwanto dan Dyah Ratih Sulistyastuti (2012:65) menjelaskan bahwa implementasi "establish a link that allows goals of public politicies to be realized as outcomes of governmentasl activity".

Menurut Ripley (1985) yang dikutip oleh Purwanto dan Dyah Ratih Sulistyastuti $(2012 ; 71)$ menjelaskan proses implementasi kebijakan yaitu bagaimana setelah melalui serangkaian proses yang panjang suatu kebijakan kemudian mampu mewujudkan tujuan atau sasaran yang dicapai. Pendapat ini melihat bahwa suatu keberhasilan implementasi tidak hanya berhenti pada kepatuhan para implementer saja, namun hasil yang dicapai setelah prosedur implementasi dijalani perlu dilihat secara detail dengan mengikuti proses implementasi itu dilalui.

Berdasarkan pemaparan diatas dapat disederhanakan bahwa tahapan kinerja implementasi adalah hasil kinerja/efek yang diterima setelah kelompok sasaran menerima policy output yang dihantarkan oleh implementing agency.

\subsection{Perpustakaan Perguruan Tinggi}

Menurut Sulistyo Basuki (1991:51)perpustakaan perguruan tinggi adalah perpustakaan yang terdapat pada perguruan tinggi, badan bawahannya, maupun lembaga yang berfaliasi dengan perguruan tinggi, dengan tujuan utama membantu perguruan tinggi mencapai tujuannya yakni Tri Dharma Perguruan Tinggi (pendidikan, penelitian dan pengabdian masyarakat). Peraturan pemerintahan PP Nomor 24 tahun 2014 dijelaskan bahwa perpustakaan perguruan tinggi adalah perpustakaan yang merupakan bagian integral dari kegiatan pendidikan, penelitian dan pengabdian kepada masyarakat dan berfungsi sebagai pusat sumber belajar untuk mendukung tercapainya tujuan pendidikan yang berkedudukan di perguruan tinggi.

Mengacu definisi tersebut dapat disimpulkan bahwa perpustakaan perguruan tinggi adalah perpustakaan yang terdapat pada perguruan tinggi yangberfungsi menyediakan dan menyebarluaskan informasi guna membantuperguruan tinggi 
tersebut mencapai tujuannya yakni Tri Dharma Perguruan Tinggi (pendidikan, penelitian, dan pengabdian masyarakat).

\subsection{Peran Pendidikan Standar ACRL}

Standar terbaru ACRL yang diterbitkan oleh American Library Association (ALA) dan dipublikasikan pada oktober 2011, terdapat sembilan prinsip didalamnya yaitu;

1. Institutional Effectiveness (Efektifitas Institusi)

2. Proffessional Values (Nilai-nilai Profesional)

3. Educational Role (Peran Kependidikan)

4. Discovery (Penemuan)

5. Collections (Koleksi)

6. Space (Ruang)

7. Management Administration (Manajemen Administrasi)

8. Personnel (Personil)

9. External Relations (Hubungan Eksternal)

Menurut ACRL prinsip educational role/prinsip pendidikan disebutkan terdapat 6 indikator didalamnya yaitu;

1. Staf perpustakaan berkolaborasi dengan fakultas berkaitan dengan cara mengakses koleksi dan layanan perpustakaan ke dalam pengalaman pendidikan yang efektif bagi mahasiswa.

2. Staf perpustakaan berkolaborasi dengan fakultas untuk menanamkan hasil pembelajaran literasi informasi ke dalam kurikulum, mata kuliah, dan tugas- tugas.

3. Staf perpustakaan memperagakan praktik pengajaran di kelas pengajaran di ruang kelas, desain tutorial online, dan praktik kependidikan lainnya.

4. Staf perpustakaan membuat panduan dalam berbagai konteks dan membuat modul untuk belajar mandiri bagi mahasiswa.

5. Staf perpustakaan berkolaborasi dengan mitra kampus untuk memberikan kesempatan bagi pengembangan profesional dosen.

6. Perpustakaan memiliki infrastruktur teknologi informasi (TI) untuk menjaga kemutakhiran perkembangan teknologi pengajaran dan pembelajaran.

Maksud dari prinsip peran pendidikan dalam Standar ACRL (2011:09) adalah menjadi mitra dalam misi pendidikan institusi untuk mengembangkan dan mendukung pembelajaran literasi informasi yang mampu menemukan, mengakses, dan menggunakan informasi secara efektif untuk keberhasilan akademik, penelitian, dan pembelajaran sepanjang hayat. Standar ACRL memiliki contoh indikator kerja dalam penerapannya sepert ipenjelasan berikut ini (2009:15) this appendix provides sample outcomes for selected performance indicators. It isexpected that each library will develop its own outcomes based on the mission and goals of the institution, dari pemaparan tersebut dijelaskan bahwa didalam standar ACRL terdapat contoh penerapan untuk indikator kinerja. Indikator kinerja disini merupakan keseluruhan indikator kinerja dari 9 prinsip yang ada pada standar ACRL yang bisa dipilih dan dikembangkan sendiri oleh perpustakaan dalam mendukung visi misi dari perpustakaan tersebut.

Berikut ini adalah isi dari prinsip peran pendidikan serta contoh indikator keberhasilannya :

1. Staf perpustakaan berkolaborasi dengan fakultas berkaitan dengancaramengakses koleksi dan layanan perpustakaan ke dalam pengalaman pendidikan yang efektif bagi mahasiswa. Adapun contoh indikator keberhasilan meliputi :

a. Fakultas mencari masukan dari pustakawan dalam pengembangan mata kuliah dan tugas.

b. Mahasiswa yang menggunakan koleksi perpustakaan untuk kebutuhan informasi kurikuler dan non-kurikuler meningkat.

c. Mahasiswa dan dosen respek terhadap perpustakaan, dan keahlian personil 
perpustakaan, dan pentingnya arti belajar sepanjang hayat.

d. Mahasiswa dan dosen mengartikulasikan pentingnya nilai perpustakaan dalam pengalaman pendidikan mahasiswa.

e. Mahasiswa dan Fakultas berkonsultasi dengan pustakawan perihal pekerjaan yang memerlukan sumber daya informasi.

f. Fakultas menekankan pentingnya pembelajaran sepanjang hayat baik kepada mahasiswa maupun dalam silabus.

2. Staf perpustakaan berkolaborasi dengan Fakultas untukmenanamkanhasilpembelajaran literasi informasi ke dalam kurikulum, mata kuliah, dan tugas-tugas. Adapun contoh indikator keberhasilan meliputi :

a. Fakultas memasukkan hasil pembelajaran literasi informasi dalam silabus.

b. Fakultas memperkenalkan dan memperkuat hasil pembelajaran literasi informasi melalui desain tugas.

c. Fakultas mensyaratkan mahasiswa menunjukkan hasil literasi informasi yang lebih canggih sebelum menyelesaikan studi.

d. Mahasiswa menunjukkan keterampilan dan kemampuannya dalam literasi informasi.

e. Mahasiswa memasukkan berbagai sumber daya yang tepat dalam bibliografi.

f. Mahasiwa mengartikulasikan alasan/ rasional untuk mengevaluasi sumber daya.

3. Staf perpustakaan praktek memberikan pengajaran dikelas, tutorial secara online, dan praktik kependidikan lainnya. Adapun contoh indikator keberhasilan meliputi :

a. Mahasiswa menilai kelas yang diberikan oleh pustakawan adalah efektif dan menarik.

b. Mahasiswa menilai tutorial online bersifat edukasi dan menarik

c. Dosen menghargai masukan pustakawan dalam teknik pengajaran dan pembelajaran.
4. Staf perpustakaan membuat panduan dalam berbagai konteks dan membuat modul untuk belajar mandiri bagi mahasiswa. Adapun contoh indikator keberhasilan meliputi :

a. Perpustakaan menyediakan modul untuk pembelajaran mandiri yang bisa diakses lewat akses virtual dan disampaikan didalam kelas di fakultas.

b. Siswa dapat memilih antara beberapa pilihan instruksi yang ada dimodul, memilih metode yang disukai mereka.

c. Fakultas mencari cara mengajarkan kemampuan literasi informasi yang sesuai dengan gaya belajar yang beragam dari para mahasiswa.

5. Staf perpustakaan berkolaborasi dengan mitra kampus untuk memberikan kesempatan bagi pengembangan profesional Fakultas. Adapun contoh indikator keberhasilan meliputi :

a. Fakultas berpartisipasi dalam lokakarya dan kesempatan profesional lainnya yang ditawarkan oleh perpustakaan dengan partner kampus lainnya.

b. Fakultas mengakui bahwa cara evaluasi literasi informasi sebagai suatukonsekuensi dari pengembangan profesional yang melibatkan perpustakaan.

c. Fakultas menilai bahwa mahasiswa memperoleh peningkatan pengetahuan setelah menerapkan keterampilan literasi informasi yang melibatkan perpustakaan.

d. Fakultas menilai pustakawan sebagai kolaborator dalam pendidikan mahasiswa.

e. Fakultas mengakui bahwa pustakawan sebagai sumber bantuan bagi mahasiswa.

f. Mitra kampus mengakui nilai dari berkolaborasi dengan perpustakaan membuat Fakultas berkesempatan mengembangankan profesionalitasnya.

6. Perpustakaan memiliki infrastruktur teknologi informasi (TI) untuk menjaga kemutakhiran 
perkembangan teknologi pengajaran dan pembelajaran.Adapun contoh indikator keberhasilan meliputi :

a. Mahasiswa menilai perpustakaan sebagai teknologi yang canggih.

b. Mahasiswa menggunakan teknologi dalam belajar dan berkomunikasi dengan personil perpustakaan

c. Fakultas menilai metode pengajaran perpustakaan menggunakan teknologi yang cukup memadai untuk tujuan pengajaran.

\section{Metode Penelitian}

\subsection{Jenis Penelitian}

Jenis penelitian yang digunakan adalah kualitatif, penelitian kualitatif adalah penelitian yang dimaksudkan untuk memahami fenomena tentang apa yang dialami oleh subjek penelitian secara holistik dengan cara mendiskripsikan dalam format kata-kata dan bahasa, pada suatu konteks khusus yang alamiah dan dengan memanfaatkan berbagai metode alamiah

\subsection{Subjek dan Objek Penelitian}

Menurut Arikunto (2000:116) subjek adalah benda, hal, orang atau tempat data untuk variabel penelitian melekat dan yang dipermasalahkan. Subjek dari penelitian ini adalah implementasi standar peranpendidikan berdasarkan Standart Asociation Of College \& Research Libraries, sedangkan objek penelitiannya adalah Perpustakaan FK UGM.

\subsection{Teknik Pengumpulan Data}

Penelitian ini menggunakan wawancara semi terstruktur Sugiyono (2009:233) dimana dalam pelaksanaannya lebih bebas bila dibandingkan dengan wawancara terstruktur.

Informan penelitian menggunakan teknik penentuan informan dengan menggunakan purposive sampling dalam Sugiyono (2009: 122) menyatakan bahwa sampel purposive adalah teknik penentuan sampel dengan pertimbangan tertentu.. Informan yang menjadi pelaku dalam pengimplementasian yang terdapat dalam standar peran pendidikan pada staff Perpustakaan Fakultas Kedokteran Universitas Gadjah Mada.

\subsection{Teknik Analisis Data}

Data yang akan diteliti adalah berupa data kualitatif Bungin (2008:104) data kualitatif jenis data yang diungkapkan dalam bentuk kalimat serta uraian-uraian, bahkan dapat berupa cerita pendek. Data kualitatif amat

bersifat subjektif, oleh karena itu penulis akan berusaha sedapat mungkin untuk menghindari sikap subjektif yang dapat mengaburkan objektifitas penelitian.

Analisis Data Kualitatif menggunkan model Miles dan Huberman dalam Sugiyono (2009:246) ada tiga metode dalam analisis data kualitatif, yaitu reduksi data, model data, penarikan/verifikasi kesimpulan.

\section{Hasil dan saran}

\subsection{Gambaran Umum Perpustakaan Fakultas Kedokteran UGM}

Perpustakaan Fakultas Kedokteran UGM terletak di Jalan Farmako, Sekip, Yogyakarta. Gedung Unit Perpustakaan Kedokteran UGM terdiri dari 2 lantai seluas $2.216 \mathrm{~m}^{2}$. Lantai satu digunakan untuk koleksi buku, layanan akses internet, administrasi perpustakaan, pemrosesan bahan pustaka, dan layanan photo copy. Lantai dua digunakan untuk layanan karya ilmiah, home theater, ruang CBT, dan Unit Teknologi Informatika Fakultas Kedokteran Universitas Gadjah Mada Yogyakarta.

Perpustakaan sebagai unit kerja di Fakultas Kedokteran UGM, dalam menjalankan tugas pokok Unit Perpustakaan FK UGM selalu berusaha untuk mendukung pencapaian visi dan misi lembaga induk yang menaunginya. Tugas pokok tersebut ialah:

1. Mengadakan, memproses, menyediakan, dan memberikan layanan literatur bidang biomedis, klinik, kesehatan masyarakat, gizi, keperawatan, dan bidang ilmu terkait lainnya yang mendukung kegiatan pendidikan, 
penelitian dan pengabdian bagi segenap civitas akademika Fakultas Kedokteran Universitas Gadjah Mada maupun masyarakat akademik pada umumnya.

2. Memberikan bimbingan penelusuran literatur untuk meningkatkan pemanfaatan sumber daya informasi yang tersedia dan menumbuhkan semangat belajar mandiri (independent learning) dan belajar sepanjang hayat (lifelong learning).

3. Memfasilitasi akses terhadap sumber informasi ilmiah terkini yang tersedia secara inhouse maupun online.

4. Mendokumentasi karya tulis ilmiah civitas akademika Fakultas Kedokteran Universitas Gadjah Mada dalam upaya mengembangkan local contents sebagai sumber daya informasi institusi yang dapat diakses oleh masyarakat luas.

Koleksi perpustakaan merupakan sumber daya informasi yang terus dikembangkan agar dapat memenuhi kebutuhan informasi dan referensi dosen maupun mahasiswa. Koleksi yang tersedia di perpustakaan berupa buku cetakatauelektronik, jurnal, karya tulis ilmiah cetak atau elektronik, multimedia dan database. Selain dibutuhkan oleh mahasiswa UGM, koleksi karya tulis ilmiah juga banyak dimanfaatkan oleh mehasiswa dari luar UGM baik dari wilayah dalam maupun luar kota Yogyakarta. Koleksi karya tulis ilmiah disediakan dalam format cetak maupun elektronik. Koleksi dalam format elektronik masih dilayankan terbatas dalam jaringan lokal (intranet) Fakultas Kedokteran Universitas Gadjah Mada. Perpustakaan tidak melanggan jurnal cetak. Koleksi diperoleh sebagai hasil pertukaran pengiriman Journal of The Medical Sciences (Berkala Ilmu Kedokteran) yang diterbitkan oleh Fakultas Kedokteran Universitas Gadjah Mada 4 kali setahun. Perpustakaan FK UGM menyediakan koleksi buku dalam format cetak dan digital.

Unit Perpustakaan FK UGM untuk memberikan kemampuan menelusur literature dilakukan melalui beberapa kegiatan, antara lain sosialisasi layanan bagi mahasiswa baru, Blok 1.1 Literature Searching, dan Defisiensi TI untuk mahasiswa S2 IKM.

\begin{tabular}{|c|c|c|c|}
\hline No. & Program Studi & Jumlah Peserta & Tangaal \\
\hline 1. & $\begin{array}{l}\text { Pendidikan } \\
\text { Dokter - } \\
\text { Program } \\
\text { Reguler }\end{array}$ & 225 Mahasiswa & $\begin{array}{l}31 \text { Agustus - } \\
4 \text { September } \\
2015\end{array}$ \\
\hline 2. & $\begin{array}{l}\text { Pendidikan } \\
\text { Dokter- } \\
\text { Program } \\
\text { Internasional }\end{array}$ & 105 Mahasiswa & $\begin{array}{l}\text { 8-11 } \\
\text { September } \\
2015\end{array}$ \\
\hline 3. & $\begin{array}{l}\text { Program } \\
\text { Studi S2 } \\
\text { Keperawatan }\end{array}$ & 54 Mahasiswa & $\begin{array}{l}8 \text { September } \\
2015\end{array}$ \\
\hline 4. & $\begin{array}{l}\text { Program } \\
\text { Studi S2 IImu } \\
\text { Pendidikan } \\
\text { Kedokteran }\end{array}$ & 15 Mahasiswa & $\begin{array}{l}10 \\
\text { september } \\
2015\end{array}$ \\
\hline 5. & $\begin{array}{l}\text { Program } \\
\text { Studi S2 IKM }\end{array}$ & 440 Mahasiswa & \begin{tabular}{|l} 
4-15 \\
September \\
2015 \\
\end{tabular} \\
\hline 6. & $\begin{array}{l}\text { Program } \\
\text { Studi S1 IImu } \\
\text { Keperawatan }\end{array}$ & 80 Mahasiswa & \begin{tabular}{|l}
16 \\
September \\
2015 \\
\end{tabular} \\
\hline 7. & $\begin{array}{l}\text { Program } \\
\text { Studi S1 Gizi } \\
\text { Kesehatan } \\
\end{array}$ & 74 Mahasiswa & $\begin{array}{l}17 \\
\text { September }\end{array}$ \\
\hline 8. & $\begin{array}{l}\text { Mahasiswa } \\
\text { Elektif }\end{array}$ & 35 Mahasiswa & $\begin{array}{l}7-8 \\
\text { Desember } \\
2015\end{array}$ \\
\hline
\end{tabular}

Sumber:LaporanTahunanUnitPerpustakaanFKUGMTahun2015.

\subsection{Implementasi Prinsip Peran Pendidikan Berdasarkan Standar ACRL di Perpustakaan FK UGM}

Mengacu rumusan masalah pada penelitian ini, maka agar pemaparan hasil penelitian ini menjadi lengkap dan menyeluruh, mengacu teori tahapan implementasi yang dikemukakan oleh Erwan Agus 
Purwanto dan Dyah Ratih Sulistyastuti.

Proses tahapan Implementasi tersebut digambarkan sebagai berikut:

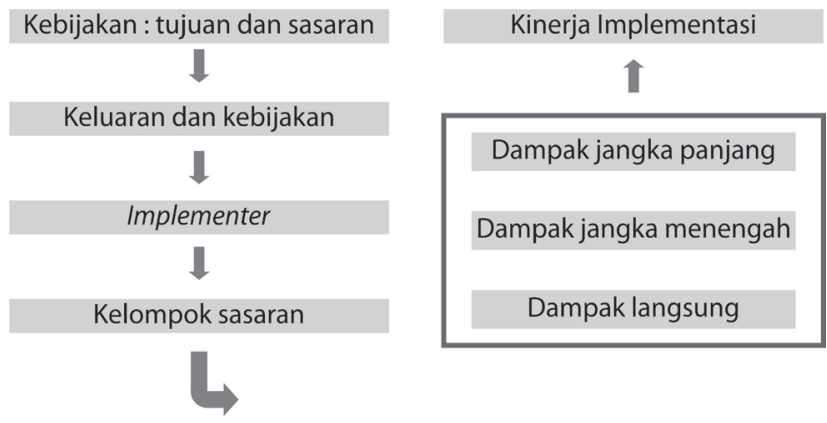

Sumber : Purwanto (2002)

Merujukgambaran proses tahapan implementasi diatas, dalam penelitian dipaparkan menjadi 6 point sebagai berikut;

1. Latar belakang, Tujuan dan Sasaran Impelementasi Standar ACRL

Tahapan pertama merupakan tahapan kebijakan: tujuan dan sasaran, pada tahapan ini akanpenulis jelaskan mengenai latar belakang, tujuan serta sasarandari perpustakaan FK UGM dalam mengimplementasikan standar ACRL.

2. Tahapan Keluaran dan Kebijakan Prinsip Peran Pendidikan

Kemudian tahapan kedua yaitu tahapan keluaran dan kebijakan dari tahapan ini penulis akan menjelaskan mengenai pembuatan rencana program kerja dari pengimplementasian prinsip peran pendidikan yang dilakukan oleh Perpustakaan FK UGM.

3. Tahapan Implementer

Kemudian tahapan yang ketiga adalah penulis akan menjelaskan tentang siapa saja yang menjadi implementer/ implementing agency dalam prinsip peran pendidikan ini atau yang terlibat dalam pengimplementasian program kerja peran pendidikan.

4. Kelompok Sasaran

Tahapan yang keempat yaitukelompok sasaran. Pada tahapan ini penulis akan memaparkan kelompok-kelompok yang menjadi sasaran dalam pengimplementasian prinsip peran pendidikan di Perpustakaan FK UGM.

5. Target Jangka Pendek, Menengah dan Jangka Panjang dari Implementasi Peran Pendidikan di Perpustakaan FK UGM. Pada tahapan ini penulis akan menjelaskan target jangka pendek, jangka menengah dan jangka panjang dari implementasi peran pendidikan yang Perpustakaan FK UGM akukan.

6. Kinerja Impelementasi Prinsip Peran Pendidikan Di Perpustakaan FK UGM Dan yang terakhir adalah tahapan pemarapan dari kinerjaimplementasi peran pendidikan yang dilakukan oleh perpustakaan FK UGM.

Tahapan ini penelitia akan menjelaskan implementasi dari 6 point prinsip peran pendidikan yang dilakukan oleh Perpustakaan FK, dan akan penulis jelaskan apakah 6 point prinsip peran pendidikan sudah terlaksana atau belum terlaksana sesuai isi dari 6 point prinsip peran pendidikan.

\subsubsection{Latar Belakang, Tujuan dan Sasaran dari Implementasi Standar ACRI di Perpustakaan FK UGM}

Kebijakan implementasi standar ACRI yang dilakukan oleh Perpustakaan FK UGM tentunya mempunyai latar belakang dan faktor-faktor tertentu yang membuat kebijakan tersebut diterapkan. Adapun salah satu alasan yang melatar belakangi Perpustakaan FK UGM dalam mengimplementasikan Standar ACRL dijelaskan dalam hasil wawancara dibawah ini:

"Inikan dalam rencana 5 tahun kedepan mulai tahun 2013 harapannya kita menjadi sebuah perpustakaan yang sesuai dengan standar-standar yang ada kalau mengacu pada standar nasional tentu perpustakaan ini sudah mencapai standar nasional sehingga kita akan mengacu pada sebuah standar internasional ACRL."

(wawancara dengan penanggungjawab perpustakaan, 16 Mei 2016) 
Hasil wawancara diatas menjelaskan bahwa salah satu alasan yang menjadi latar belakang diimplementasikannya standar ACRL adalah karena perpustakaan ingin memiliki sebuah standar perpustakaan yang mana bila mengacu pada standar nasional sudah terpenuhi, maka dari itu Perpustakaan FK UGM menerapkan standar internasional ACRI.

Alasan lain mengapa perpustakaan FK UGM menerapkan standar internasional karena perpustakaanjuga mengacu pada visi misi fakultas yang ingin menjadi fakultas berstandar internasional seperti yang terlihat dalam websiteresmifakultas kedokteran FK UGM dalam http://fk.ugm.ac.id/visi-misi/dibawah ini:

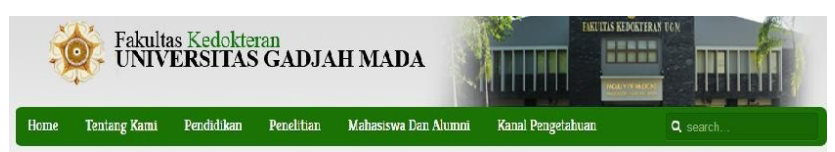

VISI \& MISI

VISI:

Mejadi fakultas yang berstandar internasional yang novatif dan ıngg̨u serta senantiasa mengabdi paca kepentingan bangsa dan kemanusiaan.

MISI:

Menirgkatkan status kesehatan masyarakat mela au kegiatan pendidikan, penelitian, pengabcian dan pelayanan yang unggul, berlandaskar kearifan lokal, etika, profesionalisme dan keimuan berbasis tukt.

Gambar 1: Visi Misi FK UGM

Hal tersebut tentu ada korelasi dan hubungannya karena secara struktural Perpustakaan FK UGM berada di bawah Fakultas Kedokteran, maka dari itu Perpustakaan FK UGM harus mendukung visi \& misi dari FK UGM sebagai unit fasilitas pendukung pembelajaran di FK UGM.

\subsubsection{Keluaran Kebijakan Prinsip Peran Pendidikan di Perpustakaan FK UGM}

Tahapan keluaran kebijakan seperti yang dijelaskan sebelumnya adalah rencana program kerja untuk mencapai sebuah tujuan dan sasaran dari sebuah kebijakan.Melalui reduksi data yang penulis lakukan, Adapun tahapan Keluaran kebijakan ataupun rencana progam kerja untuk pengimplementasian prinsip peran pendidikan di Perpustakaan FK UGM mengacu pada kebijakan strategis yang dibuat oleh Perpustakaan FK UGM, seperti yang dijelaskan melalui hasil wawancara dibawah ini:

"Program kerja itu kita buat didalam rencana kegiatan perpustakaan selama 3 tahun didalam draft rencana strategis pengembangan perpustakaan ada timeline rencana kegiatan apa yang akan kita lakukan pertahunnya dan itu akan kita wujudkan dalam RKAT kita mengacu pada targettarget yang sudah tercapai didalamnya saya waktu menyusun kegiatan setiap tahunnya RKAT ya mencermati dari rencana strategis pengembangan perpustakaan tersebut."

(wawancara dengan penanggungjawab perpustakaan, 16 mei 2016)

Berasarkan hasil wawancara tersebut dijelaskan program-program kerja untuk standar ACRL terdapat dalam timelinedraft kebijakan strategis, didalamnya penulis menemukan beberapa rencana program kerja untuk prinsip peran pendidikan yang akan dilakukan dari tahun 2014-2016 terdapat dalam draft Kebijakan strategis perpustakaan FK UGM,Program kerja tersebut diantaranya:

1. Pelatihan literature searching bagi mahasiswa setiap tahun dilaksanakan 1 kali

2. Update modul literature searching setiap tahun dilaksanakan 1 kali

3. Menyelenggaraan bedah buku karya dosen FK setiap tahun dilaksanakan 1 kali.

Mengacu pernyataan diatas dapat disimpulkan bahwa program-program kerja tersebut menjadi keluaran kebijakan atau instrument dari implementasi peran pendidikan yang dilakukan oleh Perpustakaan FK UGM.

\subsubsection{Implementer Prinsip Peran Pendidikan di Perpustakaan FK UGM.}

Tahapan selanjutnya adalah tahapan implementer yang didalam teori Erwan Agus Purwanto dan D R Sulistyastuti disebut juga implementing agency Erwan Agus Purwanto dan D R Sulistyastuti (2012:73) menjelaskan implementing agency 
adalah lembaga yang diberi tugas untuk mengimplementasikan kebijakan. Berkaitan dengan yang menjadi implementer/ implementing agency dalam standar ACRL di Perpustakaan FK UGM dijelaskan dalam wawancara dibawah ini;

"Yang terlibat dalam pengimplementasian standar peran pendidikan adalah semua staf namun memiliki porsi peran yang berbeda-beda sesuai kemampuan mereka masing-masing", contoh ada pustakawan yang mempunyai kemampuan dia secara langsung memberi materi pada menelusur literatur pada mahasiswa pendidikan dokter ada yang sebagai mentor utama dan ada yang sebagai pendamping pada proses waktu memberikan literature searching hampir semuanya mempunyai peran."(wawancara dengan penanggungjawab perpustakaan, 16 mei 2016)

Hasil wawancara tersebut mengandung arti bahwa semua staf terlibat dalam pelaksanaan standar peran pendidikan namun peran dan porsinya yang berbeda- beda, seperti dalam program kerja peran pendidikan pelatihan literature searching yang melibatkan semua staf perpustakaan namun ada yang keterlibatannya secara penuh dan ada juga sekedar sebagai pendamping dalam kegiatan tersebut.

\subsubsection{Kelompok Sasaran Implementasi Prinsip Peran Pendidikan di Perpustakaan FK UGM.}

Pelaksanaan implementasi prinsip peran pendidikan di perpustakaan FK UGM dalam pembuatan kebijakan menargetkan kelompok sasaran adalah seluruh mahasiswa dan dosen FK UGM. Terutama fokus kepada mahasiswa pendidikan dokter seperti yang dijelaskan dalam reduksi data dibawah ini;

"Dari mahasiswa,dosen dan kalangan masyarakat umum kita undang, tanpa kita pungut biaya sudah ada dana untuk kegiatan itu, kita kerjasama dengan humas fakultas yang menginformasikan keluar mengenai kegiatan bedah buku tersebut." (wawancara lbu Ngesti gandini, 27 Mei 2016)

Beradasar reduksi data diatas dapat diambil kesimpulanyang menjadi kelompok sasaran dalam kegiatan pelatihan literasi informasi adalah seluruh civitas akademika FK UGM. Program kerja yang lain yaitu update modul literature juga memiliki kelompok sasaran yaitu seluruh civitas akademika FK UGM yang memakai modul tersebut dalam pembelajaran secara mandiri. Modul ini hanya diuplod di jaringan intranet maka modul-modul tersebut hanya bisa diakses dalam lingkungan FK UGM.

4.2.5. Rencana Jangka Pendek, Menengah, dan Jangka Panjang dari Implementasi Prinsip Peran Pendidikan di FK UGM

Tahapan selanjutnya dalam mengetahui rencana target implementasi prinsip peran pendidikan, baik jangka menengah atau jangka panjang. Tahapan ini agar implementasi kebijakan menjadi terukur dan lebih mudah untuk dilakukan. Target untuk implementasi prinsip peran pendidikan dijelaskan melalui hasil wawancara dibawah ini:

"Targetnya yaitu yang terdapat dalam RKAT tahunan, RKAT itu kita buat sesuai dengan rencana strategis yang sudah kita buat relevansinya ada di RKAT dan kemudian kita membuat schedule dalam kegiatan dalam RKAT itu misalnya pelatihan itu tanggal berapa bulan berapa kita rumuskan diawal tahun sampai betul-betul semua itu bisa tercapai dalam satu tahun tersebut kita schedule kan disitu yang kita lakukan nah nanti bentuknya adalah laporan tahunan itu merupakan gambaran kegiatan yang kita lakukan dalam satu tahun untuk laporan yang kemudian kita laporkan kepada dekan dan wakil dekan."

(wawancara dengan penanggungjawab perpustakaan, Mei 2016)

Target jangka panjang dalam implementasi peran 
pendidikan dan ACRL terdapat dalam penyusunan rencana pengembangan Unit Perpustakaan FK UGM adalah sebagai berikut:

1. Menyediakan kebutuhan sumber informasi yang lengkap dalam berbagai format bagi civitas akademika FK UGM

2. Menjadi perpustakaan yang maju dengan sistem layanan modern.

3. Menjadi perpustakaan rujukan bagi Perpustakaan FK atau STIKES di Indonesia

4. Menjadi pelopor jaringan kerjasama Perpustakaan FK dan STIKES di Indonesia.

\subsubsection{Kelompok Sasaran Implementasi Prinsip} Peran Pendidikan di Perpustakaan FK UGM.

Pelaksanaan implementasi prinsip peran pendidikan di perpustakaan FK UGM dalam pembuatan kebijakan menargetkan kelompok sasaran. Sasaran yang dibuat adalah seluruh mahasiswa dan dosen FK UGM. Terutama lebih fokus kepada mahasiswa pendidikan dokter seperti yang dijelaskan dalam reduksi data dibawah ini;

"Dari mahasiswa, dosen dan kalangan masyarakat umum kita undang, tanpa kita pungut biaya sudah ada dana untuk kegiatan itu, kita kerjasama dengan humas fakultas yang menginformasikan keluar mengenai kegiatan bedah buku tersebut." (wawancara Ibu Ngesti gandini, 27 Mei 2016)

Berdasarkan reduksi data diatas dapat diambil kesimpulanyang menjadi kelompok sasaran dalam kegiatan pelatihan literasi informasi adalah seluruh civitas akademika FK UGM. Program kerja yang lain yaitu update modul literature juga memiliki kelompok sasaran seluruh civitas akademika FK UGM. Tujuan agar civitas dapat memakai modul tersebut untuk pembelajaran secara mandiri. Modul ini hanya diuplod di jaringan intranet sehingg modul-modul tersebut hanya bisa diakses dalam lingkungan FK UGM.

\section{Penutup}

\subsection{Kesimpulan}

Berdasarkan pembahasan hasil penelitian yang Berjudul Implementasi Prinsip Educational Role

Di Perpustakaan Fakultas KedokteranUniversitas Gadjah Mada Berdasarkan Standar Association Of College And Research Libraries. Kesimpulan dari penelitian ini adalah sebagai berikut:

1. Implementasi prinsip peran pendidikan di Perpustakaan FK UGM berdasarkan standar ACRL dilaksanakan melalui program kerja pelatihan literature searching, update modul literatur searching, dan bedah buku karya dosen FK UGM. Disamping itu juga penyediaan fasilitas TI untuk mendukun gproses pembelajaran berupa fasilitas Wifi, koleksi referensi online dan teknologi RFID Circulation Assistant di perpustakaan.

2. Berdasarkan 6 point prinsip peran pendidikan 5 point sudah berjalan sesuai rencana kerja yang dibuat, namun ada 1 point prinsip peran pendidikan yang belum terlaksana, yaitu "Staf perpustakaan berkolaborasi dengan mitra kampus untuk memberikan kesempatan bagi pengembangan profesional dosen". Program bedah buku Perpustakaan FK UGM yang direncanakan dilakukan satu kali setiap tahun dari mulai 2014-2016, namun baru terlaksana 1 kali pada tahun 2014 dan pada tahun 2016 belum ada rencana untuk pelaksanaannya.

\subsection{Saran}

Saran yang dapat peneliti berikan untuk pengembangan implementasi dari standar ACRL prinsip peran pendidikan adalah:

1. Mempertahankan program-program kerja prinsip peran pendidikan yang sudah berjalan dan terlaksana sesuai rencana.

2. Menambah dan terus mengupdate fasilitas TI untuk untuk mendukung pembelajaran dan pengajaran di Perpustakaan FK UGM.

3. Mengevaluasi program kerja bedah buku yang 
belum berjalan sesuai target yang rencanakan.

4. Melakukan evaluasi secara keseluruhan dan secara berkesinambungan untuk meningkatkan kinerja, pelayanan, kualitas dan kuantitas dari setiap indikator programproram kerja prinsip peran pendidikan yang sudah berjalan.

\section{Daftar Pustaka}

Anonim. 2011. "Standards for Libraries inHigher Education". Didownload Melaluihttp://www.ala. org/acrl/sites/ala.org.acrl/files/content/standards/ slhe.pdf, tanggal 28januari 2016, pukul 19:30.

Anonim. 2016. "Kamus Lengkap". Didownload melaluihttp://kamuslengkap.com/kamus/inggrisindonesia/arti-kata/implementor, tanggal 9 september 2016

Arikunto, Suharsimi. 2000. Manajemen Penelitian. PT. RinekaCipta. Jakarta

---------. 1998. Prosedur Penelitian Suatu Pendekatan Praktek. PT. Rineka Cipta. Jakarta.

Basuki, Sulistyo. 1991. Pengantar Ilmu Perpustakaan. Jakarta: Gramedia Utama

Bungin, M. Burhan. 2008. "Penelitian Kualitatif". Jakarta: Kencana Prenada Media Group

Duch, J. Barbara.1995. "Problems: A Key Factor in PBL". [Online].Dalam http://www.udel. edu/pbl/cte/spr96-phys.html, tanggal29 januari2016, pukul 20.00.Dunn, William N. 2000. "AnalisisKebijakanPublik". Yogyakarta : Gadjahmada University Press.

Moleong, Lexy. 2006. Metodologi Penelitian Kualitatif. PT. Remaja Rosdakarya. Bandung.

Mudjiono, Ricky dan FX. Dicky Prihermono. W. 2008. "Kamus Umum Bahasa Indonesia". Scientific Press. Jakarta.

Purwanto, E.A dan Dyah R.S. 2002. Implementasi KebijakanPublik. Yogyakarta: GavaMedia.

Sugiyono. 2009. "Metode Penelitian Kuantitatif Kualitatif dan $R \& D^{\prime \prime}$. Bandung: Alfabeta.

Universitas Gadjah Mada. 2014. "Draft Kebijakan Strategis Rencana Pengembangan
UnitPerpustakaan Fakultas Kedokteran Universitas GadjahMada. Yogyakarta: Unit Perpustakaan Fakultas Kedokteran Universitas Gadjah Mada. 